\title{
SOBRE PEDRA, ARQUITETURA E RESTAURO
}

\author{
Mário Mendonça de Oliveira
}

\author{
Professor Programa de Pós-graduação em Arquitetura e Urbanismo da UFBA
}

mmo1936@gmail.com

Resumo: O texto mostra, em rápidas pinceladas, a importância da pedra como material de construção, através dos tempos, demonstrando como o nascimento da arquitetura monumental coincide com o domínio do trabalho sobre os materiais líticos. Destaca, em seguida, como os diversos momentos da Cultura do Mundo Ocidental encararam o trabalho da cantaria, nas suas edificações, e o progressivo distanciamento da formação dos arquitetos do conhecimento do uso da pedra nos edifícios, bem como da ciência da sua conservação. Enfatiza-se, igualmente, a necessidade de preparação científica para enfrentar os problemas da degradação dos materiais líticos dos edifícios modernos e antigos, trazendo alguns exemplos de intervenções sobre os mesmos.

Palavras Chave: pedra, cantaria, conservação

Abstract: ABOUT STONE, ARCHITECTURE AND CONSERVATION. The text shows, in rapid brushstrokes, the importance of stone as a building material through the ages, demonstrating how the birth of monumental architecture coincides with the domain of the work on lithic materials. Then, it points out how, in various moments, Western Culture had used stonework in its buildings, and how architects are getting progressively alienated from the knowledge of the use of stone in buildings, as well as the science of its conservation. It is also emphasized the need for scientific preparation to deal with the problems of the degradation of lithic materials, in both modern and ancient buildings, showing examples of restoration works done on them.

Keywords: stone, stonework, conservation

\section{PRELIMINARES}

Dizia o nosso bom Heródoto que a história é "a mestra da vida", e o fato de termos ensinado, por mais de trinta e dois anos, a matéria História da Arquitetura, nos concede a veleidade de imaginar que a pedra é um dos materiais mais importantes dessa nobre arte. Nota-se claramente, fazendo revisão crítica da evolução das técnicas, que, quando o homem conseguiu dominar o trabalho com esse material, saiu da simples atividade construtiva para introduzir, nos seus edifícios, a preocupação estética do tratamento das formas. Conseguiu, finalmente, a concretização da tríade vitruviana da firmitas, utilitas et venustas, que caracteriza aquela construção que pode ser apelidada de arquitetura. Porém a pedra, muito mais do que simples material construtivo, trata-se de matéria de significado transcendental, cuja presença é prenhe de simbolismos que levaram a grandes estudiosos da antiguidade, como Aristóteles (384 a.C - 322 a.C), Plínio (23 - 79), Avicena (980 - 1037) e mesmo teólogos como Alberto Magno (1193-1280), a refletirem sobre a sua materialidade e significado, invocando para isto os elementos constituintes da velha alquimia - a terra, o ar, o fogo e a água. No momento, estamos deixando de fora, de propósito, os nomes de Teofrasto e Vitrúvio, porque estes estudaram os materiais líticos como especialistas.

Estas nossas reflexões vêm a propósito decerto fato paradoxal que temos constantemente observado. Se aqueles que se ocupam do estudo das rochas alcançaram, na sua maioria, um conhecimento mais aprofundado do material, mercê do arsenal de instrumentos que a moderna ciência nos trouxe, os usuários das pedras andaram no

doi: $10.18285 /$ geonomos.v24i2.837 sentido inverso do seu conhecimento, perdendo aquela intimidade com o material, confidência que possuíam os mais antigos, mesmo dentro do empirismo da sua sabedoria. Convenhamos, tal fato não pode deixar de ser motivo de preocupação. É bom observar que, pelo menos, desde o IV século antes de Cristo, já se escrevia sobre as pedras. Teofrasto de Lesbos (c. 372 - 287 a.C) ${ }^{1}$ foi um dos autores notórios, que se debruçaram sobre o argumento, talvez influenciado pela escola peripatética de Aristóteles, da qual foi seguidor. Sobre elas sentenciava o ilustre pensador e estudioso das ciências da terra: [...] porém, o poder daquelas usadas em trabalhos manuais é mais conhecido e encontrado em maior variedade, porque algumas podem ser esculpidas, ou torneadas ou serradas; existem algumas nos quais uma ferramenta de ferro não consegue trabalhar, $e$ outras nas quais trabalha mal e com dificuldade. $E$ há várias outras diferenças além destas [... $]^{2}$.

O documento, todavia, que nos trouxe, pela vez primeira, com grande propriedade, a voz dos conhecimentos do passado, em ralação ao uso das pedras na arquitetura foi, podemos afiançar, o Arquitetura Decem Libri, de Vitrúvio Polião (ou Polio), profissional da construção, cuja existência pode ser datada do primeiro século antes de Cristo. Este fato pode ser inferido do seu próprio texto, quando faz encômios ao Imperador Otavio (Gaius Julius Caesar Otavianus), ou seja, antes que assumisse o título de Augusto, em 27 a.C. Logo, o nosso arquiteto deve ter visto a aurora do Império Romano sem que saibamos, todavia, quando nasceu e morreu exatamente. Dedica o autor um trecho

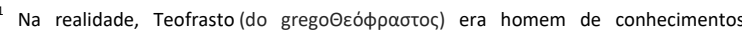
interdisciplinares que iam da filosofia às Ciências Naturais e, dentro delas, dedicou um dos livros às pedras.

${ }^{2}$ THEOPHRASTUS. On Stone.Tradução e comentários de Earle Caley e John Richards. Columbus, Ohio: The Ohio State University, 1956. p.48.
} 
substancial ao nobre material, emitindo sobre ele preciosas e abalizadas informações no livro II. O experiente arquiteto (ou engenheiro militar como querem alguns) demonstra, no seu texto, já conhecer os efeitos do intemperismo sobre algumas rochas, como gelo-degelo, tensão de cristalização de sais solúveis, stress térmico, embora, na explicação do fenômeno enverede pela velha alquimia dos quatro elementos ${ }^{3}$. Para melhor detalhamento de como os antigos autores, arquitetos, engenheiros ou não, trataram o conhecimento das pedras recomendamos a leitura do trabalho de Santiago sobre os materiais de construção ${ }^{4}$.

\section{A PEDRA NA ARQUITETURA}

Durante muito tempo acreditou-se que a antiga Civilização do Egito tinha sido o berço da arquitetura. Porém, as descobertas arqueológicas efetivadas no Oriente Próximo e no Vale do Indus, a partir do fim do século XIX e durante a primeira metade do Século XX, subtraíram ao Vale do Nilo esta primazia. Ninguém pode, contudo, disputar-lhe o privilégio de ter dominado, pela primeira vez, com maestria, o manejo e a técnica de trabalhar sobre os materiais líticos, mesmo com os instrumentos, os mais rudimentares, e operando, por vezes, sobre rochas duríssimas como os granitos e os granodioritos de Assuã, os basaltos do deserto e outras rochas eruptivas. Pelos testemunhos encontrados nos vestígios arqueológicos da arquitetura funerária egípcia é voz geral, entre os estudiosos da história da arquitetura, que foi na pirâmide escalonada de Zozer ou Djoser, faraó da Terceira Dinastia, onde a pedra foi entronizada, em larga escala. O edifício em questão foi trabalhado com refinamentos, nunca dantes encontrados em monumentos, como no magnífico friso dos "uraeus" ${ }^{5}$ (Figura 1) e no pórtico de colunas proto-dóricas (Figura 2). Essa obra-prima de arquitetura funerária, edificada em pedra calcária, imortalizou o seu autor, o arquiteto Imhotep.

Do Período Medieval da Cultura do Mundo Ocidental seria até ocioso fazer qualquer lembrete, porque os castelos e, principalmente as catedrais, foram e ainda são, os testemunhos mais eloquentes de que a pedra foi o material por excelência, como o foi no Egito Antigo. O fervor religioso da fé cristã e o elã de verticalidade, simbolizando a busca de Deus, levaram ao limite a capacidade de trabalho dos materiais líticos, deixando-nos, como memória daqueles tempos, extraordinários edifícios religiosos. As catedrais, cujas estruturas pétreas desafiavam as leis da estática, passaram à moderna historiografia como as "bíblias feitas de pedra", em virtude da variada, profusa e belíssima iconografia religiosa arrancada da dureza desse material.

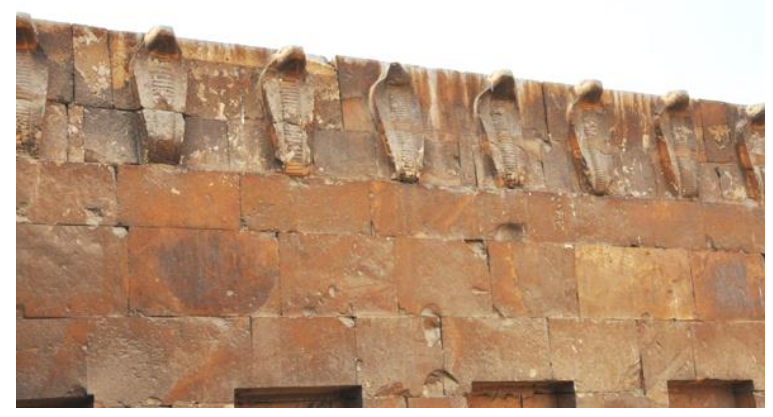

Figura 1. Friso dos "uraeus" no conjunto funerário da pirâmide escalonada de Sakara. Fonte: acervo do autor

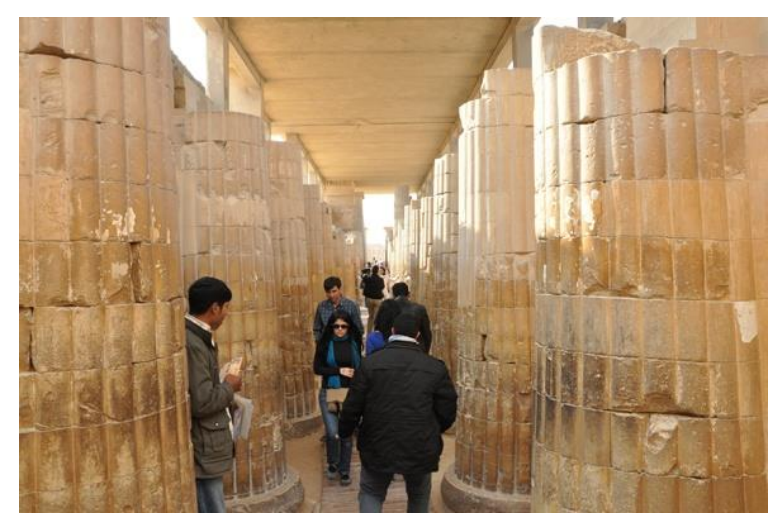

Figura 2. Colunas proto-dóricas no conjunto funerário de Sakara. Fonte: acervo do autor.

Vem o Renascimento e, com o advento dos tratadistas da arquitetura, a partir do final do Século $\mathrm{XV}$, encabeçados pelo renomado Leon Batista Alberti e seu De re Edificatoria ${ }^{6}$, o assunto das pedras nos edifícios tornou-se, praticamente, uma constante, em todos os textos mais importantes. As exceções são poucas, como o texto historiográfico do Vasari $^{7}$ (1511 - 1574) ou o compêndio de Vignola ${ }^{8}$ (1507 1573), por ter, este último, escopo fundamentalmente gráfico. Também, não poderia ser de outra maneira, pois todos eles eram seguidores confessos (ou não) dos ensinamentos de Vitrúvio, de quem repetiam as lições sobre o caráter e a propriedade dos principais materiais pétreos empregados na Itália, acrescentando observações de vivência e tirocínio nos canteiros da profissão. É desta época que emerge novo trabalho literário, especificamente dedicado às pedras aplicadas na arquitetura, nos ornamentos e nos objetos de arte,
${ }^{3}$ VITRUVIO Pollio. De architectura. Torino: Giulio Einaudi, 1997. v.1, I.1, p. 137 Organização de Pierre Gros e tradução de Antonio Corso e Elisa Romano.

${ }^{4}$ SANTIAGO, Cybèle Celestino. Estudo dos materiais de construção de Vitrúvio até ao Século XVIII - Uma visão crítica e interpretativa à luz da ciência contemporânea. Évora: Tese de doutorado apresentada a Universidade de Évora, 2001.

${ }^{5}$ Ornato em forma de serpente que enfeitava a coroa dos faraós e a fronte das imagens de alguns deuses, inspirado na serpente naja (Naja tripudians).

\footnotetext{
ALBERTI, Leon Batista.

VASARI, Giorgio. Le vite de più eccelenti pittori scultori e architettori. Roma: Rusconi Libri srl, 2002. Coordenação de Jacopo Recupero.

${ }^{8}$ VIGNOLA, Giacomo Barozzi da. Regras das cinco ordens de arquitetura. Coimbra: Real imprensa da Universidade, 1787.
} 
intitulado Istoria delle Pietre, redigido pelo dominicano Agostino del Riccio ${ }^{9}$ (1541 - 1598).

\section{O NEFASTO DISTANCIAMENTO}

Os tempos modernos nos legaram a ciência especulativa, além da empírica que já nos acompanhava, trazendo para a subjetividade da intuição e do empirismo a objetividade da ciência, como apoio das investigações. Além do mais, nasce dentro do universo das aspirações barrocas 0 método seguro que nos legou Descartes para a busca da verdade científica. Sintomaticamente, este é o momento em que a ciência chega às artes da pedraria, sob a forma da disciplina Estereotomia, cuja difusão se faz mais efetiva, mercê da edição de livros especializados ${ }^{10}$ (Figura 3). Assim, todo o conhecimento hermético, das velhas corporações dos mestres pedreiros medievais, é decodificado através da geometria e do desenho projetivo.

A estereotomia foi disciplina dos currículos de arquitetura até os anos em que fizemos o curso dessa profissão, sob a forma de disciplina que se chamava: Perspectivas, Sombras e Estereotomia. No nosso tempo, porém, já não passava de atavismo da academia, pois os professores nada mais ensinavam da estereotomia naquela altura.

O século XVIII aproxima, mais ainda, os materiais líticos do tratamento científico dos novos tempos. É figura de destaque nestes trabalhos um arquiteto que se destacou sobremodo no projeto e na construção de grandes pontes de pedra. Esse arquiteto louvou-se na capacidade mecânica deste material, para o qual efetuou ensaios de compressão axial, bem como estribou-se nas formulações de La Hire, para o comportamento estático dos arcos, para fundamentar o seu trabalho. Estamos querendo fazer referência a Jean-Rodolphe Perronet (1708 1794), figura de proa da ciência das construções do século XVIII e brilhante membro da Academia de Ciências da França, um arquiteto que jamais poderia ter vindo dos quadros da Beaux-Arts. O seu fundamento para as grandes estruturas de pedras encontra-se em sua obra escrita, especialmente na memória apresentada à Academia de Ciências, intitulada: Memoire sur les recherches sur les moyens qui l'on pourroit employer pour construire de grandes Arches de pierre [... $]^{11}$ (Figura 4).

9DEL RICCIO, Agostino. Istoria delle Pietre. Torino: Umberto Allemandi \& C., 1996. Coordenação de Raniero Gnoli e Attila Sironi.

${ }^{10}$ BossÉ, A.La praticque du trait a preuves de ${ }^{\text {er }}$ Desargues, Lyonnais, pour la coupe da la pierre en l'architecture. Paris: Pierre Des-Hayes, 1643); FRÉzIER, M. Élémens de stereotomie a l'usage de l'architecture pour la coupe des pierres. Paris: Chez Antoine Jombert, 1760.

${ }^{11}$ PERRONET, Jean-Rodolphe. Memoire sur les recherches sur les moyens qui l'on pourroit employer pour construire de grandes Arches de pierre[...]. Paris : L'Imprimerie Nationale Exécutive du Louvre, 1793.

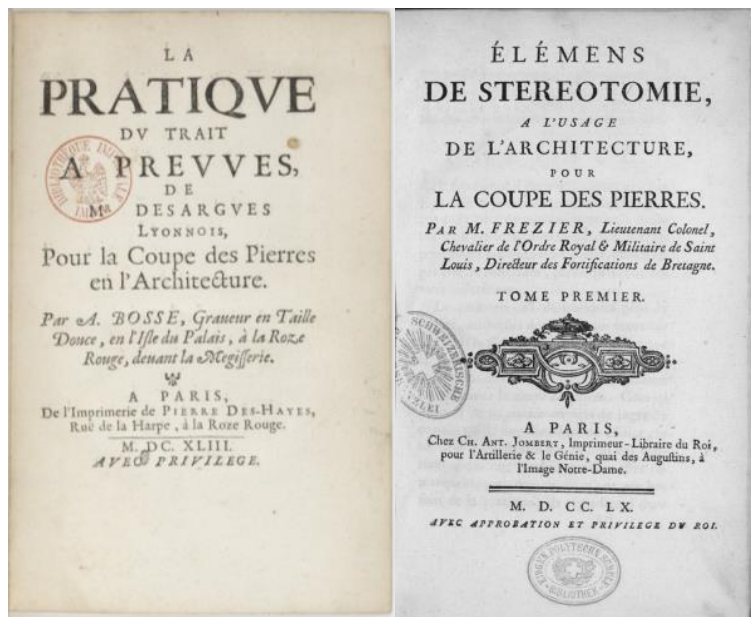

Figura 3 Folha de rosto de dois tratados de estereotomia, principalmente direcionados para o corte de pedras. O primeiro deles de Bosse (Século XVII) e o seguinte de Frézier, engenheiro militar (Século XVIII).

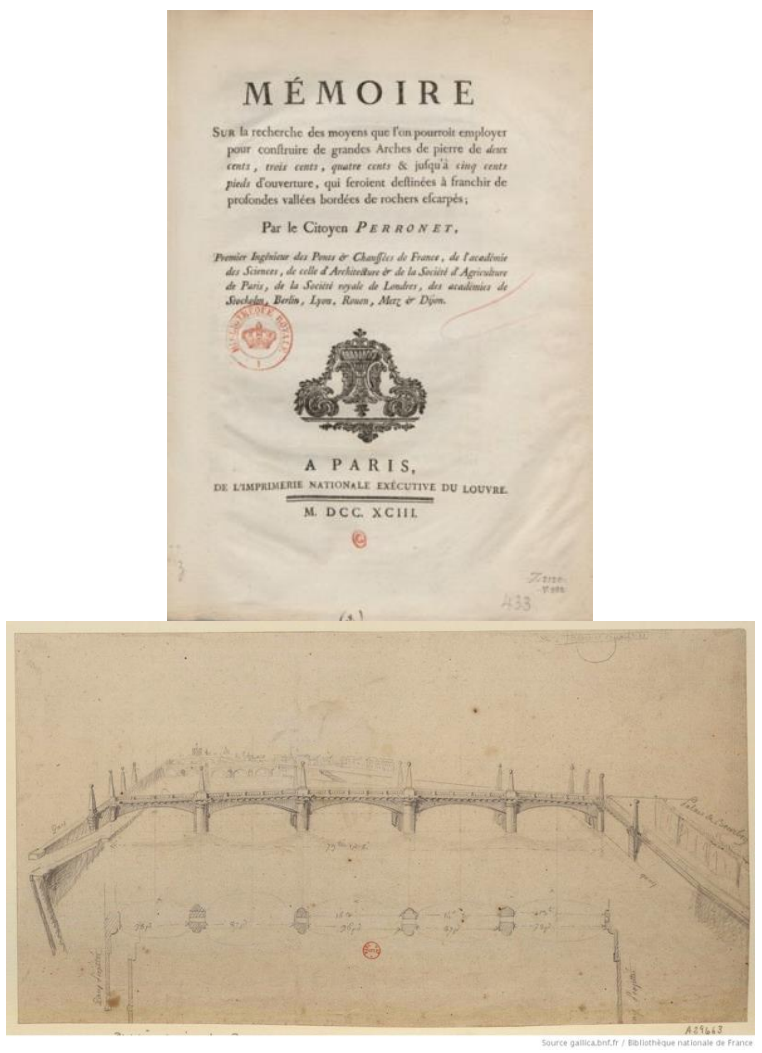

Figura 4. Memória escrita por Perronet para pontes de pedra e seu projeto preliminar para ponte, do mesmo material, sobre o

Sena, em Paris. Fonte: Bibliothèque Nationale de France.

Não obstante isso, os olhos dos profissionais de arquitetura que vieram depois não se abriram para o melhor conhecimento dos materiais dos edifícios, salvo entre os espíritos mais lúcidos. A formação acadêmica decididamente não ajudava. Regressando às comodidades dos ateliers das academias, o arquiteto voltou-se preferencialmente para o desenho, esquecendo-se que ele é somente um meio para se chegar à arquitetura, como destaca 
muito bem o mestre Gropius ${ }^{12}$. Ora, dentre os materiais de destaque do edifício encontra-se a pedra, que, pela sua complexidade geoquímica e estrutural, demanda cuidados especiais na sua extração, afeiçoamento, aplicação e conservação. Além do mais, exige muito discernimento a respeito da sua aplicação, pois não é somente a aparência que importa nesse material, mas o seu comportamento diante da função a que se destina e do local onde é aplicado. Não se trata somente de escolher materiais líticos de grande beleza plástica, para obter o efeito estético desejado, porque a pedra pode ser, muitas vezes, "bonitinha, mas ordinária", como diria o respeitado e irreverente Nelson Rodrigues!

Conhecer bem as rochas para aplicá-las à construção é, pois, um argumento básico de transcendental relevância para a arquitetura. Elas são de singular beleza, desde o domínio do microscópico ao do macroscópico e, como as mulheres, um adorno da natureza, mas tão complexas quanto estas! A imensa variedade de cores, texturas, e outras prerrogativas da sua feição, permite valorizar os espaços dos edifícios, provocando nos usuários diversificadas gradação de sensações que, vão do feérico mundano(Figura 5) ao hierático circunspecto (Figura 6).

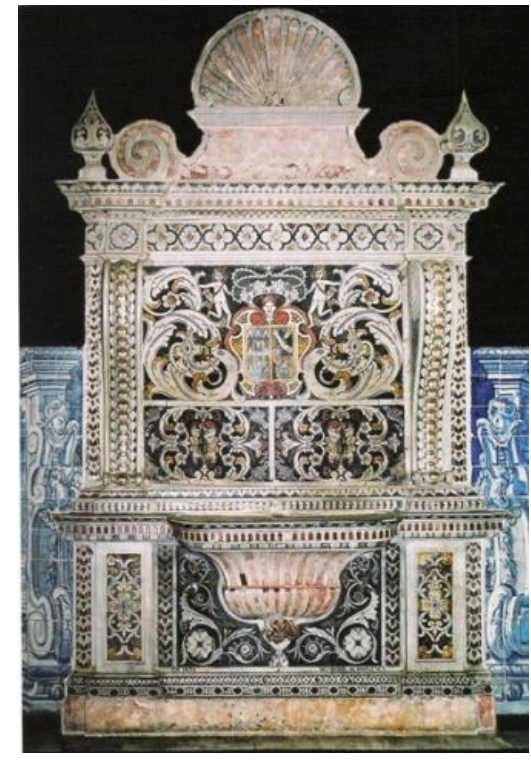

Figura 5. Lavabo da Igreja da Ordem Terceira de S. Francisco Fonte: Zenaide Silva

Os usuários dos materiais líticos dos tempos mais recentes, sejam eles arquitetos ou engenheiros, na sua mais expressiva maioria, não estão preparados para aplicá-los com discernimento e de maneira judiciosa. Do referido podemos dar testemunho, pela quantidade de problemas que nos chegam ao

${ }^{12}$ GROPIUS, Walter . The new architecture and the Bauhaus. London: Faber and Faber Ltd., 1965. p. 62. laboratório, para tentar resolver, sobre a aplicação equivocada de rochas ornamentais em edifícios modernos. A causa principal deste paradoxo é a escassa formação científica dos profissionais da construção, no seu aprendizado, principalmente por parte dos arquitetos, que continuam acreditando na estapafúrdia dicotomia que se apóia no princípio de que scientia est unum et ars est aliud, quando deviam acreditar piamente naquilo que escreveu o grande Jean Mignot, no seu notório parecer técnico para a catedral de Milão, em 1399: ars sine scientia nihil est ${ }^{13}$. Este princípio foi-nos cobrado veementemente pelo lúcido mestre Viollet-le-Duc, quando disparou contra os formados nas academias e ateliês: Nossos arquitetos, com seus predecessores, desejam apressar-se em recorrer a esta fonte de renovação? Não; eles preferem negar a influência da ciência sobre a arte ${ }^{14}$ [grifo nosso]. Temos repisado este tema durante toda a nossa vida de docente, sem medo de parecer repetitivo, em virtude da transcendência do argumento para a profissão. A grande maioria não escuta ou não quer escutar (o que é pior ainda), mas já não nos sentimos mais como outrora, um João Batista, que pregava no deserto, porque temos observado a resposta em alguns espíritos mais esclarecidos que não têm preguiça de aprender o que lhes falta e, convenhamos, faltará, sempre, um pouco mais para se aprender, não importa o quanto se saiba.

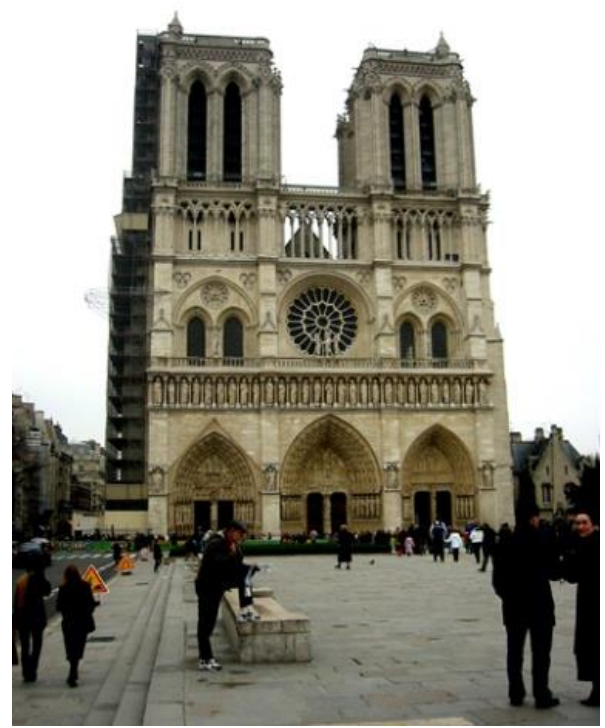

Figura 6. Nossa Senhora de Paris - Catedral gótica arcaica. Fonte: acervo do autor.

O mesmo Viollet-le-Duc, um dos pais da moderna restauração e profeta da arquitetura moderna, profissional engajado na arquitetura e no restauro, que se distraia trabalhando com os seus canteiros na obra, dizia, ao escrever à sua esposa,

\footnotetext{
${ }^{13}$ ACKERMAN, James S. "Ars sine scientia nihil est" - Ghotic theory of architecture at the cathedral of Milan. In: Art Bulletin, v.21, n.2, jun. , 1949.

${ }^{14}$ VIOLLET-LE-DUC, Eugène E. Entretiens sur l'architecture. Paris: $V^{\text {ve }}$ A. Morel \& $C^{\text {ie. }}$, 1872. Ed. facsimilada Paris: Pierre Mardaga, v.2, 1977. p. 445.
} 
quando se ocupava da restauração da Igreja da Madalena de Vezeley: Ce sont mes pierres qui sont mes confidentes et qui seules on le pouvoir de me distraire ${ }^{15}$.

Houve tempo em que a intuição preenchia, de alguma forma, a fundamentação científica dos procedimentos construtivos. Mas, esta intuição não nascia do nada. Ela era, e é, filha da experiência direta com o exercício diário da arte de construir, da tentativa e do erro e da experimentação. Jamais brotaria de quem está de posterior (como dizia meu pai!) assentado diante de uma prancheta ou de um computador. Deste modo, não podemos deixar de ter certa nostalgia do tempo em que fazíamos jus, na condição de arquitetos, ao título de Doctor Latomorum (Doutor das pedras), como foi atribuído ao mestre arquiteto Pierre de Montreil, cuja obra prima de arrojo estrutural e beleza plástica está na Santa Capela do Palácio Real, de Paris (Figura 7), onde foi conseguida a máxima aspiração gótica de "espiritualização da matéria", obtida com pedra e vidro. Este importante monumento francês sobrevive graças à restauração levada a efeito, na metade do século XIX, pelos grandes conhecedores do restauro da pedra que foram Viollet-le-Duc e Lassus.

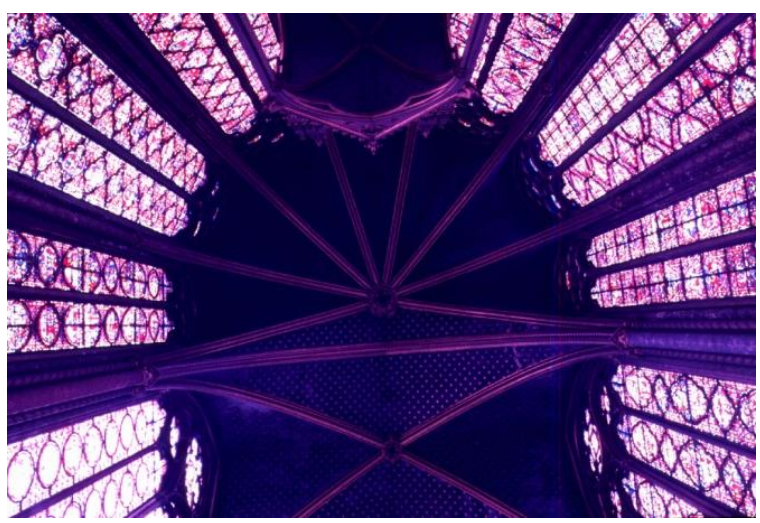

Figura 7. Santa Capela do Palácio Real. Fonte: acervo do autor.

\section{O RESTAURO DA PEDRA}

Se a fundamentação científica é exigida daqueles que aplicam as pedras nos edifícios modernos e objetos de arte, quando se trata de restaurá-las, nos artefatos antigos, esta responsabilidade de competência é acrescida muitas vezes. Todo mundo está cansado de saber que aquilo que ser restaura é a matéria, como sentencia, sempre com grande sabedoria, Cesare Brandi ${ }^{16}$. Assim sendo é exigido, da nossa parte, mergulhar, através da ciência, mais fundo ainda na intimidade dessa matéria, porque diante de um material exposto a toda a sorte de vicissitudes, que se sucedem com o correr dos anos, ${ }^{15}$ São as minhas pedras que são as minhas confidentes e somente elas têm o poder de
me distrair.

${ }^{16}$ BRANDI, Cesare. Teoria del restauro. Torino: Giulio Einaudi, 1977. p.16 o entendimento dos fenômenos de degradação pode ser bem mais complexo, bem assim como o domínio do conhecimento dos meios mais modernos de deter o processo de eversão de um edifício. É verdade, nos lembra Alois Rieg ${ }^{17}$, de maneira agourenta, que, por mais que nos esforcemos e dermos voltas ao intelecto, jamais poderemos encontrar meios de conservar, para sempre, um artefato representativo da nossa memória. Nem por isto vamos descuidar do que toca à nossa geração na missão da conservação, assim como,nem por isto, vamos deixar de cuidar de nós mesmos, não importa que saibamos que se está fadado a passar desta para a melhor!

\section{UM PAR DE EXEMPLOS DE RESTAURO E CONSOLIDAÇÃO DA PEDRA}

Muito mais eloquente do que o discurso é o exemplo e, neste momento, nos vem sempre em mente os ensinamentos do grande mestre Phillibert de l'Orme, expoente máximo do Renascimento francês: É muito melhor fazer bem do que falar bem $^{18}$. Igualmente torna-se, muito a propósito, a afirmação do nosso esclarecido Cesare Brandi de que o caminho certo de toda a teoria é desembocar “necessariamente" na prática ${ }^{19}$. Assim sendo, poderá ter cabimento, para arrematar este discurso, comentar uns dois casos emblemáticos mais recentes, entre os muitos desafios que nos foram propostos na vida profissional, demonstrando que, sem o apoio da ciência, não se vai a parte alguma no restauro. É bem verdade que, em virtude da exiguidade do espaço disponível para este texto, vamos ater-nos ao comentário de alguns aspectos, pois os relatórios técnicos detalhados preenchem dezenas de páginas.

\subsection{A cantaria do claustro do Convento de São Francisco, em Salvador}

Considerado pelos lusitanos como uma das "sete maravilhas do Mundo Português", e tombado individualmente pelo IPHAN, o conjunto da igreja e convento de São Francisco, em Salvador, dispensam comentários e elogios. Entre os inúmeros problemas que afligem 0 velho monumento ${ }^{20}$ afiguram-se aqueles que deixam sinais de degradação alarmantes no fuste das colunas toscanas (Figura 8) do claustro azulejado, comprometendo o suporte da arcaria e das abóbadas de aresta que, por sua vez, sustentam a varanda superior (Figura 9). O colapso, mesmo parcial da colunata, seria perda irreparável,

\footnotetext{
${ }^{17}$ RIEGL, Alois. II culto moderno dei monumenti - II suo carattere e i suoi inizi. Ferrara: Nuova Alfa Editoriale, 1990. p. 54.

${ }^{18}$ DE L'ORME, Phillibert. Traités d'architecture. In: Le premier tome de l'architecture de Philibert de L'Orme...Paris: Fréderic Morel, 1567. p.10. Edição facsimilada por Leonce Laget, Paris, 1988.

${ }^{19}$ BRANDI, Cesare. Op. cit. p. 55

${ }^{20}$ Estes problemas foram parcialmente resolvidos com o projeto de restauração da colunata e a execução parcial de consolidação, financiados pelo IPHAN.
} 
inclusive para a famosa azulejaria dos revestimentos parietais do claustro.

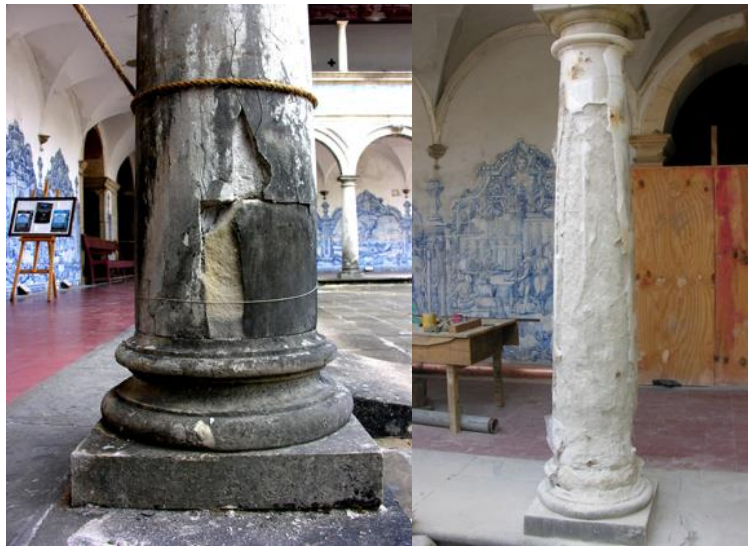

Figura 8. Estado de uma das colunas do claustro. a) Estado original; b) Removida a reintegração de cimento, sem aderência. Fonte: acervo do autor.

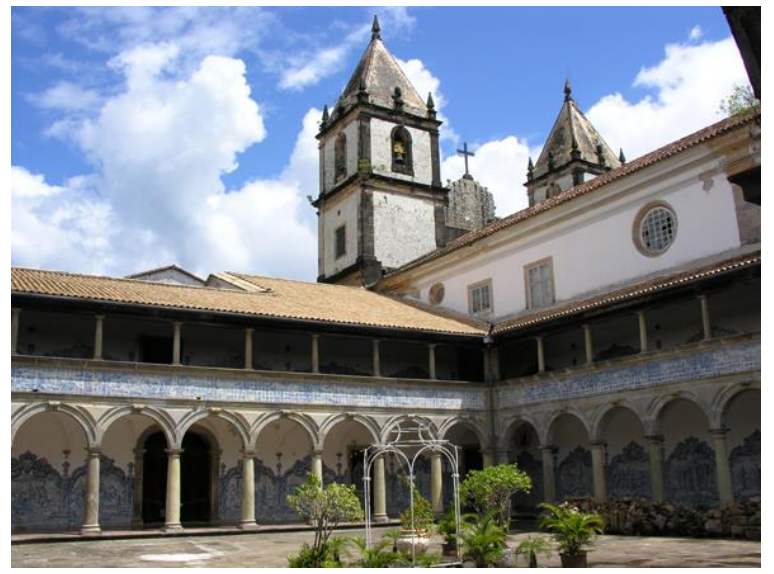

Figura 9. Claustro do Convento de São Francisco, parcialmente restaurado. Fonte: acervo do autor.

Por solicitação do IPHAN, através de projeto emergencial, fomos convocados para estudar o problema e apresentar soluções de estabilização e de restauro ${ }^{21}$. Sobre a temática já nos havíamos debruçado anteriormente quando, por simples curiosidade intelectual dirimimos, com a ajuda da ciência, certo equívoco espalhado por alguns historiadores, de que o claustro tinha sido feito com arenito da Ilha da Boipeba. Não tardou muito que este "tal" arenito estivesse aplicado, segundo eles, em muitos monumentos de Salvador, aumentando a confusão! Ora, quem possui algum rudimento de geologia não enxerga qualquer arenito no claustro (exceto no peitoril da varanda) e nem na Ilha da Boipeba existe arenito, que se saiba! Com a ajuda de um caro amigo geólogo, Professor Shiguemi Fujimori, caracterizamos, através de petrografia, o calcário que lá estava e era um dolomito. O projeto de restauro, do qual fomos encarregados, nos deu a

\footnotetext{
${ }^{21}$ Quem desejar obter mais pormenores sobre o projeto pode encontrá-lo condensado em comunicação que apresentamos à $V$ International Conference of Structural Analysis of Historical Construction, em Nova Delhi, Índia.
}

oportunidade de fazer investigação mais precisa desta rocha.

A investigação principiou pela identificação da jazida, à luz dos documentos, e o mais indicado foi o "Livro dos Guardiães" ${ }^{22}$, que dizia claramente que as pedras tinham vindo da ilha da Boipeba, mas não fala, absolutamente, que eram arenitos. A ilação equivocada ficou por conta dos referidos historiadores! Realmente, encontramos, no local denominado "Cova da Onça", na citada ilha, os vestígios da antiga jazida, de onde retiramos material sadio para ensaios em laboratório. A petrografia mostrou que o material do claustro e da jazida eram idênticos. Verificamos, em seguida, através de análise não destrutiva, a compacidade dos fustes das colunas com ultrassom, observandose que, em nove desses fustes, as emissões sequer passavam do transdutor ao receptor, em virtude de lacunas internas do material e, em outras partes, a velocidade de propagação caía muito em relação ao material sadio dos corpos de prova de laboratório. Achou-se necessário, também, a verificação do comportamento estático da estrutura, para que pudéssemos ter uma ideia das cargas que estariam suportando as colunas monolíticas, o que foi feito através do emprego de elementos finitos pela colega estruturalista do nosso grupo de pesquisas (Núcleo de Tecnologia da Preservação e da Restauração NTPR), a Prof. Rosana Muñoz.

Quanto ao material lítico tivemos a verificação inicial efetuada com o Professor Fujimori confirmada pelo nosso amigo Prof. Lorenzo Lazzarini, que, visitando o local, levou um fragmento para o seu laboratório (LAMA), em Veneza, e mandou-nos o resultado da difratometria do material bruto. Era uma rocha carbonática, nas variedades de cálcio e magnésio. Verificamos, porém, que cerca de $93 \%$ da amostra era digerido pelo ataque de $\mathrm{HCl}$, permanecendo um resíduo insolúvel, de aparência argilosa, que merecia ser investigado, pelas implicações que poderia trazer ao comportamento do material. Neste caso, funcionou o eixo SalvadorBelém, através do qual o uso da interdisciplinaridade é constante. De resto,a amizade, tem facilitado os intercâmbios, como facilita tudo na vida das pessoas. Os professores Thais Sanjad e Rômulo Angélica confirmaram, através da difratometria de raios- $X$, que o tal resíduo continha basicamente os argilominerais caulinita e ilita. O primeiro deles, sabemos, é bem comportado quanto à expansibilidade, o segundo, nem tanto. Observamos, em corpos de prova cúbicos, no nosso NTPR, que o andamento da capilaridade ascendente era

\footnotetext{
${ }^{22}$ WILLEKE, Frei Venâncio (Org. e transcrição). Livro dos guardiães do convento de São Francisco da Bahia (1587-1862). Rio de Janeiro: Ministério da Educação e da Cultura, três anos e ordenou trazer todas as pedras das colunas do claustro da Boipeba (17291732).
} 
irregular, mas tinha uma configuração semelhante à expansão dimensional do material seco quando imerso em água (Figuras 10 e 11). A presença dos argilominerais na pedra pareceu-nos, então, ser o nó da questão, combinada com a elevada porosidade observada no material e a consequente resistência mecânica pouco expressiva.

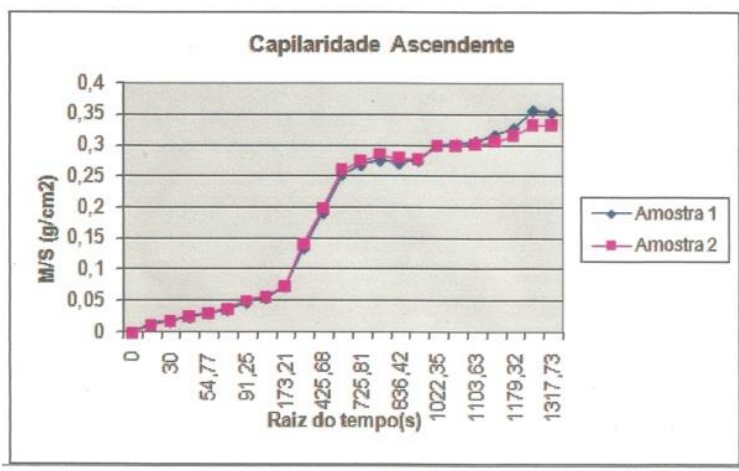

Figura 10. Gráfico de capilaridade ascendente de amostras sobre lâmina d'água. Fonte: NTPR.

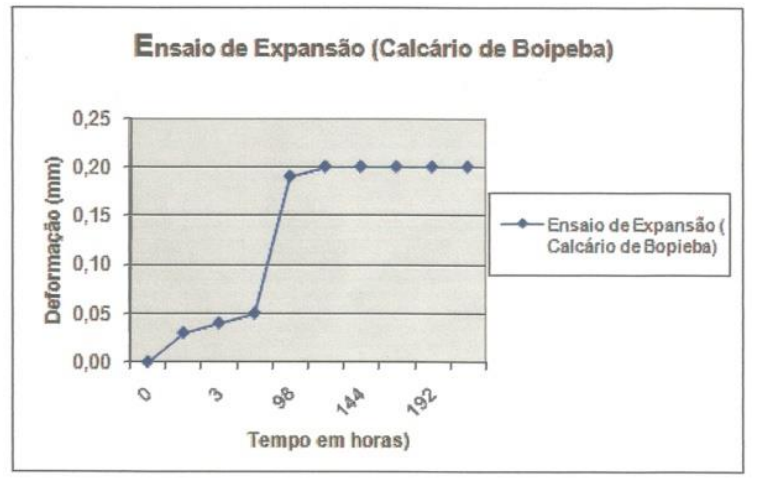

Figura 11. Gráfico de expansão da rocha quando embebida com água. Fonte: NTPR

Nas condições normais, a capacidade de carga da pedra, cuja ruptura se dava, em média, a $76 \mathrm{MPa}$, não traria qualquer sobressalto. Porém, com o material extremamente degradado, afigurou-se haver uma situação delicada para a estabilidade da estrutura. Além do mais, na ruptura de uma das amostras foi observada a presença de um equinóide fóssil completamente solto da massa carbonática e notou-se que havia, também, alguns fustes com trincas inclinadas que poderiam facilitar o colapso por cisalhamento. Junto a tudo isto era observada, em certos pontos, forte erosão provocada pela tensão de cristalização de cloretos, sulfatos e nitratos, como verificado nas análises. Em resumo, problemas para ninguém colocar defeito!

Atalhando a história, para evitar as delongas, destacamos o seguinte:

- Muitas colunas do claustro estavam (e muitas delas ainda estão) com o material lítico em péssimas condições, com grandes probabilidades de sofrer ruptura, provocando danos sérios na estrutura do claustro e na importante azulejaria da área.
- Todos os ensaios e observações indicam que a água (como quase sempre) é o principal fator de degradação e por isto devemos dificultar, de todos os modos, o seu acesso à porosidade do material lítico, especialmente aquele que provém da Ilha da Boipeba. Para isto, os beirais que tinham sido reduzidos no último entelhamento foram reconduzidos à antiga dimensão e neles foram colocadas calhas para direcionar a queda da água. As abóbadas de aresta foram impermeabilizadas no extradorso e as colunas tratadas com paralóide.

- Para resolver os problemas de estabilidade ancoramos as arquivoltas com barras de aço inoxidável, embutidas na laje sob a impermeabilização. Este sistema que criamos funcionou como contraventamento da arcaria externa. Propusemos a substituição dos fustes danificados, mas tal não aconteceu, pois a jazida está em Área de Preservação Ambiental, e a miopia intelectual dos administradores não admitiu a extração do material. Verificamos que a impregnação com resinas epoxídicas ciclo alifáticas funcionava muito bem em laboratório, mas a importação era difícil, bem como encontrar, no mercado de Salvador, bombas de vácuo possantes para trabalhar em colunas de mais de três metros de altura. Em vista disto, aplicamos tirantes antiexpulsivos no fuste, com furação em andamento helicóide, e reintegramos as lacunas com Primal e o pó da própria pedra.

As partes muito danificadas da cantaria que não tinham grande solicitação estrutural foram tratadas com próteses, como comumente se faz, e o trabalho dos canteiros foi magnífico (Figura 12).

Infelizmente, estes procedimentos só foram aplicados em metade do claustro, em virtude da tradicional escassez de recursos. O resto continua escorado, em compasso de espera. Estas restaurações, em doses homeopáticas, são um desserviço à conservação da memória construída, pois podem ensejar desastres com perdas irreparáveis.

\subsection{As pias de água benta do convento de Santo Antônio de João Pessoa}

De magnitude mais modesta foi o problema de degradação das pias de água benta do convento, também franciscano, de Santo Antônio, em João Pessoa (Figura 13), pois a degradação da pedra desses artefatos (Figura 14) não trazia implicações estruturais para o edifício ou qualquer outro objeto de interesse cultural, com exceção das pias em si.

Como de praxe, investigou-se de onde foram retiradas as pedras do monumento, inclusive das pias e, desta feita, veio em nosso auxílio a crônica de 
Frei Jaboatão ${ }^{23}$ dizendo que o material tinha sido removido das vizinhanças do convento, mas que já estava escasso. Ora, a cidade cresceu de modo que a vizinhança do convento foi ocupada por casas, eliminando qualquer possibilidade de remover material da jazida original. Felizmente, este banco de calcário aflora um pouco mais adiante da cidade e, em virtude da semelhança do material lítico, extraímos as nossas amostras deste local.

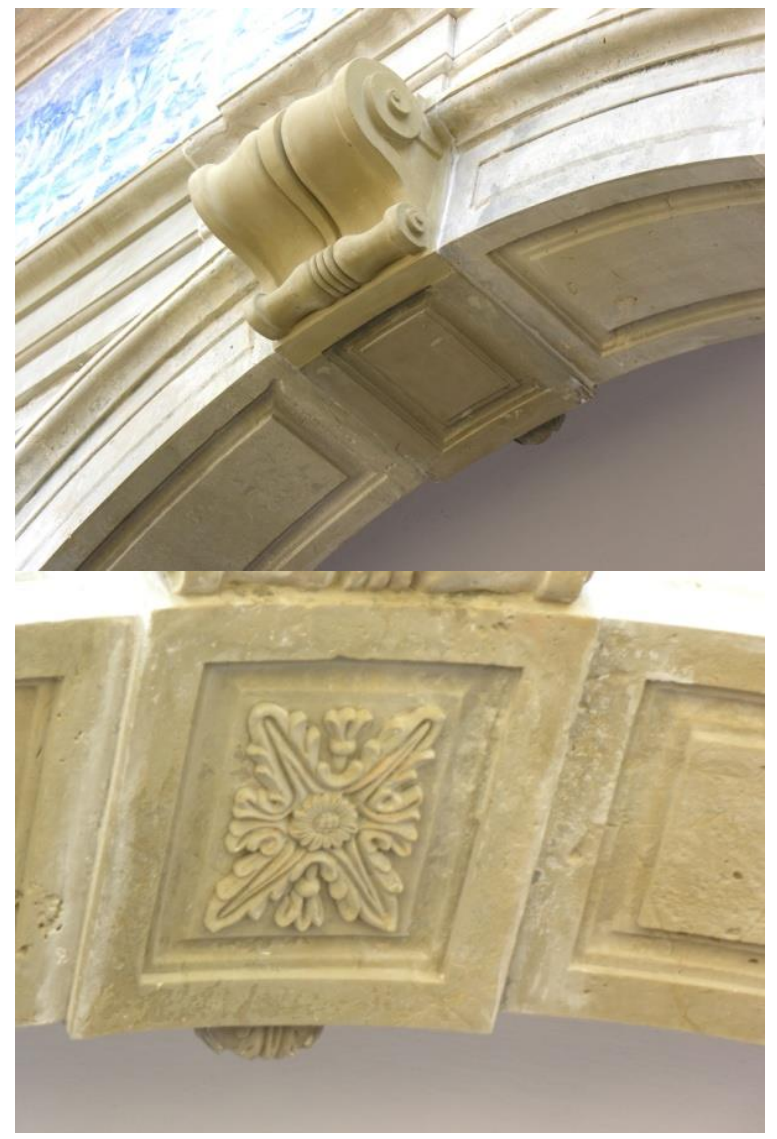

Figura 12. Reintegrações com novas peças de cantaria, executadas pelos canteiros da família Abreu, da cidade de Santa Luz. Fonte: acervo do autor.

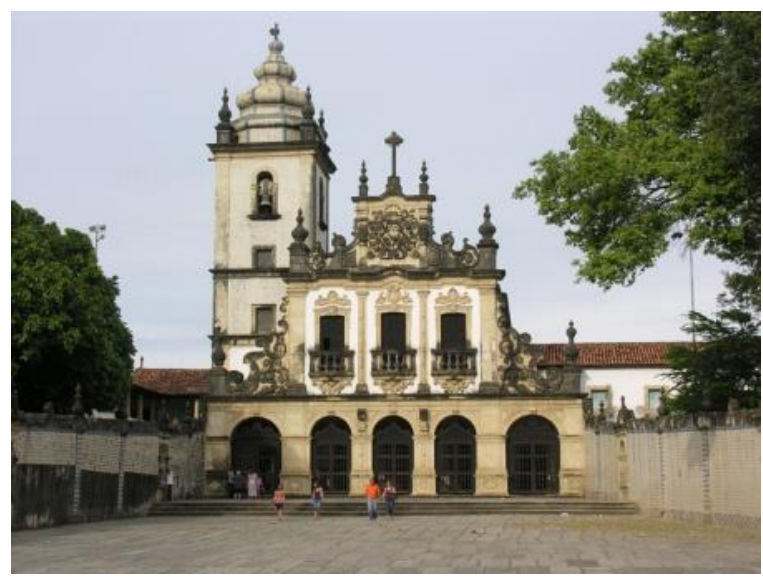

Figura 13. Convento de S. Antônio em João Pessoa. Fonte: acervo do autor.

\footnotetext{
${ }^{23}$ JABOATÃO, Frei Antonio de Santa Maria. Novo orbe serafico brasilico ou chronica dos frades menores da Província do Brasil. Recife: Assembléia Legislativa do Estado, 1980. v.1, p. 357. Edição facsimilada das edições de 1859, 1861 e 1862.
}

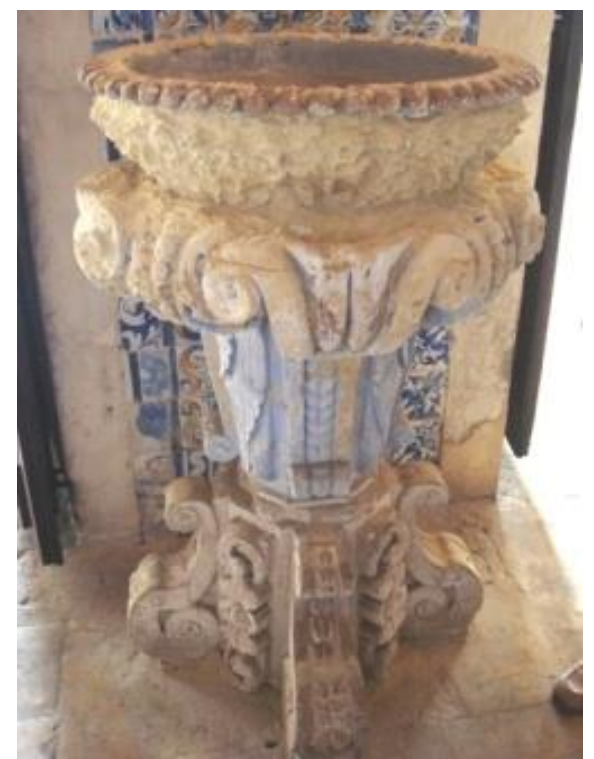

Figura 14. Uma das pias de água benta. Fonte: acervo do autor.

O diagnóstico da degradação, neste caso, foi simples. A erosão alveolar estava praticamente circunscrita às vizinhanças da bacia, onde era colocada a água benta e, como esta tem adição de $\mathrm{NaCl}$, torna este efeito nefasto comuníssimo em artefatos do gênero. O pior é que esta alveolização, por tensão de cristalização, estava em ritmo acelerado. Em um arco de tempo de seis meses, entre a nossa primeira inspeção e a aplicação do tratamento, coletou-se cerca de $3 \mathrm{k}$ de rocha pulverizada nas vizinhanças da pia!

Os ensaios nas amostras feitas no NTPR, juntamente com as análises efetuadas pelo Professor Perazzo, da UFPB, a nosso pedido, demonstraram que estávamos diante de uma marga muito mais precária do que aquela aplicada no convento de São Francisco de Salvador. Era mais porosa e, consequentemente, menos densa e a sua resistência mecânica, no material de pedreira, não chegava a uns míseros $19 \mathrm{MPa}$, na média.

Recomendou-se a aplicação de emplastros para a remoção do sal e, entre os materiais mais indicados na aplicação deste procedimento, estão as bentonitas (Figura 15). Ora, a Paraíba possui jazidas importantes desta argila. Para facilitar o processo, foi removida, de maneira mecânica, uma camada de resina termofixa que haviam aplicado no interior da bacia, aumentando a área de aplicação do emplastro e sua eficiência. Fez-se o controle dos sais na argila empastada com água destilada antes da aplicação e, sequencialmente, o material tinha o mesmo tipo de controle quando se tornava seco e se desprendia do substrato da pia até que este tornasse à situação inicial. O processo durou uns seis meses. 


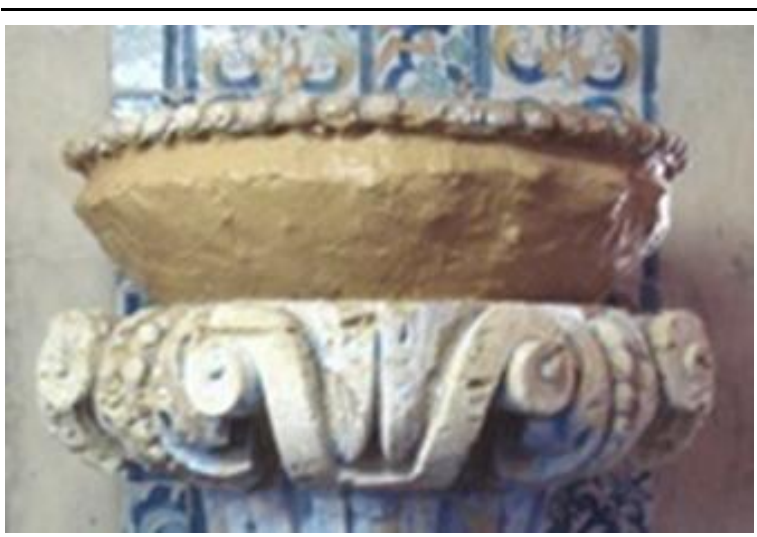

Figura 15. Primeira aplicação de pasta de bentonita. Fonte: acervo do autor.

Cerca de dois anos depois, tivemos a oportunidade de visitar o local. Não se observava mais, para a nossa satisfação, pulverulência em torno das pias. Não tinham, entretanto, feito a estucagem que sugerimos, com argamassa "bastarda" fraca, de cal, barro e areia, o que resultaria em tom pouco discrepante da pedra da pia. Não se pretendia algo para embelezamento ou tentativa de "repristinar" as pias, mas uma argamassa de sacrifício que, eventualmente, poderia absorver resíduos remanescentes de sal. Mas, estas coisas são costumeiras, pois quando o problema está resolvido, sempre aparece alguém querendo colocar a sua "colher torta", como dizia minha mãe.

\section{REFERÊNCIAS BIBLIOGRÁFICAS}

ACKERMAN, James S. "Ars sine scientia nihil est" - Ghotic theory of architecture at the cathedral of Milan. In: Art Bulletin, v.21, n.2, jun., 1949.

BOSSÉ, A.La praticque du trait a preuves de $\mathrm{M}^{\mathrm{er}}$ Desargues, Lyonnais, pour la coupe da la pierre en l'architecture. Paris: Pierre Des-Hayes, 1643).

BRANDI, Cesare. Teoria del restauro. Torino: Giulio Einaudi, 1977. p.16.

DE L'ORME, Phillibert. Traités d'architecture. In: Le premier tome de I'architecture de Philibert de L'Orme...Paris: Fréderic Morel, 1567. p.10. Edição facsimilada por Leonce Laget, Paris, 1988.
DEL RICCIO, Agostino. Istoria delle Pietre. Torino: Umberto Allemandi \& C., 1996. Coordenação de Raniero Gnoli e Attila Sironi.

FRÉZIER, M. Élémens de stereotomie a l'usage de l'architecture pour la coupe des pierres. Paris: Chez Antoine Jombert, 1760.

GROPIUS, Walter. The new architecture and the Bauhaus. London: Faber and Faber Ltd., 1965.

JABOATÃO, Frei Antonio de Santa Maria. Novo orbe serafico brasilico ou chronica dos frades menores da Província do Brasil. Recife: Assembléia Legislativa do Estado, 1980. Edição facsimilada das edições de 1859, 1861 e 1862.

PERRONET, Jean-Rodolph. Memoire sur les recherches sur les moyens qui l'on pourroit employer pour construire de grandes Arches de pierre [...]. Paris: L'Imprimerie Nationale Exécutive du Louvre, 1793.

RIEGL, Alois. II culto moderno dei monumenti-Il suo carattere e i suoi inizi. Ferrara: Nuova Alfa Editoriale, 1990. p. 54.

SANTIAGO, Cybèle Celestino. Estudo dos materiais de construção de Vitrúvio até ao Século XVIII - Uma visão crítica e interpretativa à luz da ciência contemporânea. Évora: Tese de doutorado apresentada a Universidade de Évora, 2001.

THEOPHRASTUS. On Stone.Tradução e comentários de Earle Caley e John Richards. Columbus, Ohio: The Ohio State University, 1956.

VASARI, Giorgio. Le vite de più eccelenti pittori scultori e architettori. Roma: Rusconi Libri srl, 2002. Coordenação de Jacopo Recupero.

VIGNOLA, Giacomo Barozzi da. Regras das cinco ordens de arquitetura. Coimbra: Real Imprensa da Universidade. 1787.

VITRUVIO Pollio. De architectura. Torino: Giulio Einaudi, 1997. v.1, I.1, p. 137. Organização de Pierre Gros e tradução de Antonio Corso e Elisa Romano.

WILLEKE, Frei Venâncio (Org. e transcrição). Livro dos guardiães do convento de São Francisco da Bahia (1587-1862). Rio de Janeiro: Ministério da Educação e da Cultura, 1978.

Contribuição ao

10. Simpósio Brasileiro de Caracterização e Conservação da Pedra 14 a 16 de dezembro de 2016, Congonhas - MG

Nota:

É de responsabilidade da comissão editorial do Simpósio a revisão gramatical, ortográfica, de citações e referências bibliográficas. As normas de submissão podem se diferenciar das desta revista. 